\title{
VARIABILIDADE GENÉTICA EM TRIGO AFERIDA POR MEIO DA DISTÂNCIA GENEALÓGICA E MORFOLÓGICA
}

\author{
GENETIC VARIABILITY IN WHEAT MEASURED BY \\ PEDIGREE AND MORPHOLOGICAL DISTANCE
}

\author{
Ivandro BERTAN ${ }^{1}$ \\ Eduardo Alano VIEIRA ${ }^{2}$ \\ Fernando Irajá Félix de CARVALHO ${ }^{3}$ \\ Antonio COSTA DE OLIVEIRA ${ }^{3}$ \\ Pedro Luiz SCHEEREN ${ }^{4}$ \\ Franciéle OLIVO ${ }^{5}$
}

\begin{abstract}
RESUMO
Os caracteres fenotípicos e as informações genealógicas se destacam entre as ferramentas possíveis de serem utilizadas pelos melhoristas na obtenção de estimativa da distância genética entre e dentro das espécies vegetais. Deste modo, o objetivo do trabalho foi estimar a distância genética entre genótipos de trigo sul-brasileiros, por meio do emprego de caracteres fenotípicos e do coeficiente de parentesco, e estabelecer o grau de associação entre tais técnicas. O trabalho foi realizado no município de Pelotas, localizado no Estado do Rio Grande do Sul, Brasil. Dezenove genótipos de trigo foram avaliados por três anos a campo, onde foram aferidos 17 caracteres morfológicos. Estes genótipos foram empregados na estimativa da distância fenotípica e cálculo dos coeficientes de parentesco. Os resultados revelaram ausência de associação entre as duas estimativas de distância genética avaliadas, pelo fato de não haver genealogia comum entre alguns dos genótipos testados, ou ainda, pela inexistência de dados genealógicos disponíveis de alguns genótipos. Ambas as estimativas de distância demonstraram presença de variabilidade genética entre o conjunto de genótipos de trigos sul-brasileiros avaliados. Estas diferenças podem ser exploradas na recomendação de combinações híbridas promissoras para seleção de indivíduos geneticamente superiores, de onde poderão ser obtidas novas constituições gênicas. Genótipos como BRS 177 e Rubi apresentam elevado rendimento de grãos e são divergentes fenotipicamente e genealogicamente em relação aos demais genótipos avaliados, sendo recomendados para utilização em cruzamentos artificiais com a finalidade de promover o incremento da variabilidade genética e aumento da produtividade de grãos em trigo.
\end{abstract}

Palavras-chave: dissimilaridade genética; caracteres fenotípicos; coeficiente de parentesco; melhoramento genético; Triticum aestivum $\mathrm{L}$.

\begin{abstract}
Phenotypic and pedigree data are very important tools used by breeders to estimate the genetic distance within and between plant species. Therefore, the objective of this work was to estimate the genetic distance between southern brazilian wheat genotypes, using phenotypic and pedigree data and to establish the degree of association between such techniques. The work was performed in the County of Pelotas, Rio Grande do Sul state, Brazil. Nineteen wheat genotypes were field evaluated for three years, and characterized using 17 morphological traits. These genotypes were used for calculating the phenotypic distance and coancestry coefficient estimates. The results indicate a lack of association between the two evaluated measures of distance, mainly because there is no common ancestor among the tested genotypes, or still, because of lack of pedigree data for some genotypes. Both genetic distance estimates point to the presence of genetic variability among the tested genotypes. These differences can be exploited for recommending hybrid combinations followed by selection of superior genotypes. Genotypes such as BRS 177 and Rubi present high grain yield and are fairly genetically distant from most genotypes according to both measures and should be used in artificial crosses aiming to increase wheat variability and grain yield.
\end{abstract}

Key-words: genetic dissimilarity; phenotypical traits; coancestry coefficient; plant breeding; Triticum aestivum L.

${ }^{1}$ Eng. Agro; (MSc), estudante do Programa de Pós-Graduação em Agronomia (Fitomelhoramento) em nível de doutorado, Faculdade de Agronomia Eliseu Maciel, Universidade Federal de Pelotas (FAEM/UFPel). Caixa Postal 354. CEP: 96001-970, Capão do Leão - RS - Brasil. E-mail: ivandrobertan@yahoo.com.br;

${ }^{2}$ Eng. Agro (Dr.), pesquisador da Embrapa Cerrados, BR 020, km 18, CP: 8223, CEP: 73310-970, Planaltina - DF;

${ }^{3}$ Eng. Agro (Ph.D), professor do Depto de Fitotecnia (Fitomelhoramento) da FAEM/UFPel;

${ }^{4}$ Eng. Agro (Dr.), pesquisador da Embrapa Trigo, Rodovia BR 285, km 294, CEP: 99001-970, Passo Fundo - RS;

${ }^{5}$ Eng. Agra, estudante de mestrado na Pós-Graduação em Ciência e Tecnologia de Sementes da FAEM/UFPel. 


\section{INTRODUÇÃO}

A estimativa da distância genética entre genótipos informa a respeito da organização do germoplasma, aumenta a eficiência da amostragem de genótipos, auxilia na definição de cruzamentos artificiais, na incorporação de genes exóticos (fase de pré-melhoramento) e até na recomendação de cultivares para determinadas regiões, quando o objetivo é aumentar a base genética dos cultivares sob cultivo. Assim, se constitui numa ferramenta auxiliar de grande importância em programas de melhoramento e um importante elo entre a conservação e a utilização dos recursos genéticos disponíveis (MOHAMMADI e PRASANNA, 2003).

Dentre as ferramentas utilizadas na estimativa da distância genética entre um conjunto de genótipos, destacam-se a utilização caracteres fenotípicos (morfológicos e agronômicos) e também de dados genealógicos (quando existem informações a respeito da genealogia dos genótipos avaliados), além de dados moleculares (marcadores de DNA) (BERTAN, 2005). Caracteres fenotípicos, em associação com as técnicas multivariadas, vêm sendo empregados com sucesso na quantificação da distância genética em trigo (ZEVEN e SCHACHL, 1989; VAN BEUNINGEN e BUSH, 1997; MÁRIC et al., 2004; ROY et al., 2004).

A adoção do coeficiente de parentesco como uma medida de distância é apontada como a alternativa mais fácil e barata para estimar a distância genética entre um grupo de genótipos, desde que existam informações com respeito à genealogia. $O$ coeficiente de parentesco entre dois genótipos é a probabilidade de que um alelo tomado ao acaso de um loco tomado ao acaso em um determinado genótipo seja idêntico por descendência a um alelo tomado ao acaso do mesmo loco em outro genótipo. Entretanto, um entrave para a utilização desta técnica, em grande escala, é o escasso conhecimento existente a respeito da genealogia dos genótipos (SHUT e STAN, 1997; PINZÓN-ALMANZA, 2003).

A utilização conjunta da distância genética com base em dados morfológicos e coeficiente de parentesco tem sido apresentada na literatura, principalmente com o trigo (BERED et al., 2001; MÁRIC et al., 2004) e aveia (VIEIRA et al., 2005). Os resultados demonstraram reduzida associação entre as duas estimativas, contudo, os autores ressaltam a extrema importância em considerar a variabilidade genética acessada pelas duas medidas de distância quando da recomendação de genótipos para serem empregados nos programas de melhoramento, pelo fato de elevar a qualidade da amostragem e conseqüente probabilidade de êxito no uso destes genótipos.

O presente trabalho teve como objetivo estimar a distância genética entre genótipos de brasileiros trigos, por meio do emprego de caracteres fenotípicos e do coeficiente de parentesco, e estabelecer o grau de associação destas técnicas, a fim de prover informações úteis aos melhoristas como forma de direcionar cruzamentos artificiais promissores para geração de populações segregantes superiores geneticamente.

\section{METODOLOGIA}

Nesse estudo foram avaliados 19 genótipos de trigo, cujas genealogias estão listadas na Tabela 1. Para a mensuração dos caracteres fenotípicos foram conduzidos experimentos nas safras agrícolas dos anos de 2003, 2004 e 2005, na área experimental do Centro de Genômica e Fitomelhoramento da Universidade Federal de Pelotas (CGF/UFPel), no município de Capão do Leão, localizado no Estado do Rio Grande do Sul - Brasil. O município está situado a $31^{\circ} 52^{\prime} 00^{\prime \prime}$ de latitude sul e $52{ }^{\circ} 21^{\prime} 24^{\prime \prime}$ de longitude oeste, a uma altitude de $13,24 \mathrm{~m}$. O delineamento experimental empregado foi o de blocos completos casualizados com três repetições, sendo as parcelas compostas por cinco fileiras de $5 \mathrm{~m}$ de comprimento com espaçamento de $0,20 \mathrm{~m}$ entre filas. Aárea útil da parcela foi constituída pelos $4 \mathrm{~m}$ centrais das três fileiras internas. A adubação de base foi de $300 \mathrm{~kg} \mathrm{ha}^{-1}$ de NPK (5-20-20) e mais $60 \mathrm{~kg} \mathrm{ha}^{-1} \mathrm{de}$ nitrogênio aplicado no início do afilhamento. O controle de ervas daninhas foi realizado com capina manual e o combate de formigas cortadeiras com a aplicação de iscas granuladas. O controle de pragas e moléstias foi realizado de acordo com as recomendações da COMISSÃO SUL BRASILEIRA DE PESQUISA DE TRIGO (2002).

Foram avaliados 17 caracteres fenotípicos, segundo os procedimentos apresentados por SCHEEREN (1984): i) dias da emergência ao florescimento (DEF); ii) dias da emergência a maturação (DEM); iii) dias do florescimento a maturação (DFM), iv) estatura de planta em cm (EP); v) número de afilhos férteis por metro linear (AFML); vi) peso de mil grãos em g (PMG); vii) peso do hectolitro em $\mathrm{kg} \mathrm{hL}^{-1}(\mathrm{PH})$; viii) rendimento de grãos em kg ha-1 (RG); por meio da avaliação de 25 plantas por parcela, foram estimados: ix) largura da lâmina da folha bandeira em cm (LFB); $x$ ) comprimento da lâmina da folha bandeira em $\mathrm{cm}$ (CFB); $x i$ ) comprimento da bainha em $\mathrm{cm}$; xii) comprimento do pedúnculo em cm (CP) e por meio da avaliação de 25 espigas de cada parcela, foram estimados: xii) comprimento da espiga em $\mathrm{cm}(\mathrm{CE})$; xvi) número de espiguetas por espiga (NE); $x v$ ) peso de espiga em $g$ $(\mathrm{PE})$; xvi) número de grãos por espiga (NG) e xvii) número de grãos por espigueta $\left(\mathrm{NG} \mathrm{NE}^{-1}\right)$. 
BERTAN, I. et al. Variabilidade genética em trigo...

TABELA 1 - Genótipos considerados no estudo e suas respectivas genealogias. CGF/UFPEL, Pelotas, 2007.

\begin{tabular}{ll}
\hline Genótipos & Genealogia* \\
\hline BH 1146 & PG 1//Fronteira/Mentana \\
BR 18 & Desconhecido \\
BR 23 & Correcaminos/AlondraSib/3//AS 54-20/Cotiporã//CNT 8 \\
BR 35 & IAC 5*2/3/cnt 7*3/Londrina//IAC5/Hadden \\
BRS 49 & BR35/PF83619//PF858/PF8555 \\
BRS 119 & PF82252/BR35//IAPAR17/PF8550 \\
BRS 120 & PF83899/PF813//F27141 \\
BRS 177 & PF83899/PF813//F27141 \\
BRS 194 & CEP14/BR23//CEP17 \\
BRS 208 & CPAC 89118/3/BR 23//CEP 19/PF 85490 \\
CEP 24 & BR3/CEP7887//CEP7775/CEP11 \\
CEP 29 & BR23/CEP8423//Buc Sib \\
BRS 192 & PF869114/PF8722 \\
PF 950354 & Embrapa16/Pat73-92 \\
Rubi & PF869107/Klein H3450C3131 \\
Sonora 64 & Yaktana54/Norin10B17//2*Yaqui54 \\
TB 951 & TB 108//BR 23 *2/PF 869114 \\
ICA 1 & Embrapa16/PF97504//CEP14/Coker762 \\
ICA 2 & Pampainta/CEP24//BR43 \\
\hline
\end{tabular}

* os sinais $/, / /, / 3 /, \ldots, / X /$ indicam a ordem em que os cruzamentos foram realizados; os retrocruzamentos estão simbolizados com um asterisco ( $\left(^{*}\right)$ e o número indica o número de retrocruzamentos com o genitor recorrente. /: indica o primeiro cruzamento realizado, //: 0 segundo e .../X/: o x-ézimo cruzamento efetuado. Essa metodologia é semelhante à proposta por PURDY et al. (1968).

Os dados dos caracteres fenotípicos foram submetidos à análise de variância considerando os efeitos de genótipos como fixos e dos anos como aleatório. As médias dos caracteres avaliados, nos três anos, foram comparadas por meio da distância mínima significativa (DMS) a $5 \%$ de probabilidade. Posteriormente, foi estimada a distância generalizada de Mahalanobis $\left(D^{2}\right)$ entre todos os pares de genótipos, com base nas médias dos três anos de avaliação, por meio do programa computacional Genes (CRUZ, 2001). Com base na matriz de distância genética, foi construído um dendrograma, utilizando o método de agrupamento da distância média (UPGMA). O ajuste entre a matriz de distâncias e o dendrograma foi estimado pelo coeficiente de correlação cofenética (r) (SOKAL e ROHLF, 1962), por meio do programa computacional NTSYS pc 2.1 (ROHLF, 2000).

O cálculo do coeficiente de parentesco (COP) foi efetuado de acordo com sistema de cálculo de parentesco de Malécot, empregando a genealogia apresentada na Tabela 1 e também as genealogias auxiliares descritas nas literaturas de ZEVEN e ZAVEN-HISSINK (1976) e ZEVEN e REINER (1991) e obtidas junto a pesquisadores de centros de pesquisa em trigo que desenvolveram os genótipos avaliados. Os coeficientes foram estimados com auxílio do programa computacional SAS (SAS LEARNING EDITION, 2002). Posteriormente, a similaridade genética estimada foi transformada em dissimilaridade genética segundo a equação:

$D_{\alpha \beta}=1-S_{\mu}$ onde que $D_{\alpha \beta}$ corresponde aos

coeficientes de dissimilaridade genética e $\mathrm{S} \mu$ corresponde aos coeficientes de similaridade genética. A partir desta matriz, foi construído um dendrograma e medido o ajuste do mesmo para com a matriz de dissimilaridade utilizando os mesmos programas computacionais utilizados para os dados fenotípicos.

Para a estimativa da correlação (associação) entre as matrizes de distância obtidas por meio da análise de caracteres fenotípicos e da distância genealógica, foi empregado o teste de comparação de matrizes de Mantel, com 1000 permutações (MANTEL, 1967), por meio do programa computacional NTSYS pc 2.1 (ROHLF, 2000).

\section{RESULTADOS E DISCUSSÃO}

Os resultados da análise de variância evidenciaram a existência de diferenças genéticas entre os genótipos estudados, uma vez que foram detectadas diferenças significativas $(P<0,05)$ para todos os caracteres fenotípicos avaliados, para a fonte de variação genótipos (Tabelas 2 e 3), o que reforça a necessidade da análise multivariada por meio da estimativa da distância genética entre as constituições genéticas avaliadas. Também foi possível observar diferenças significativas, a $5 \%$ de probabilidade pelo teste DMS, para as fontes de variação de anos e para a interação genótipos $x$ anos, para a maioria dos caracteres avaliados, o que justifica a necessidade da avaliação das constituições genéticas por mais de um ano, sendo tão mais precisas quanto maior o número de anos avaliados (Tabelas 2 e 3). Também, é possível observar que os coeficientes de variação foram de baixa magnitude, variando de 1,93 a 16,13\%, revelando assim a elevada precisão experimental do trabalho. 
BERTAN, I. et al. Variabilidade genética em trigo...

TABELA 2 - Comparação de médias e resumo das análises de variância de nove caracteres avaliados em 19 genótipos de trigo. CGF/ UFPEL, Pelotas, 2007.

\begin{tabular}{|c|c|c|c|c|c|c|c|c|c|}
\hline \multirow[b]{2}{*}{ Genótipos } & \multicolumn{9}{|c|}{ Caracteres } \\
\hline & $\begin{array}{c}\mathrm{DEF}^{(+)} \\
\text {(dias) }\end{array}$ & $\begin{array}{l}\text { DEM } \\
\text { (dias) }\end{array}$ & $\begin{array}{l}\text { DFM } \\
\text { (dias) }\end{array}$ & $\begin{array}{c}\text { EP } \\
(\mathrm{cm})\end{array}$ & $\begin{array}{l}\text { AFML } \\
\text { (unid.) }\end{array}$ & $\begin{array}{l}\text { LFB } \\
(\mathrm{cm})\end{array}$ & $\begin{array}{l}\text { CFB } \\
(\mathrm{cm})\end{array}$ & $\begin{array}{c}\mathrm{CB} \\
(\mathrm{cm})\end{array}$ & $\begin{array}{l}\mathrm{CP} \\
(\mathrm{cm})\end{array}$ \\
\hline BH 1146 & 73,44 & $133,89 s$ & 60,44 & $100,22 s$ & 79,00 & 1,36 & 19,28 & $19,08 s$ & 23,65 \\
\hline BR 18 & 74,56 & 123,44 & 48,89 & $78,44 \mathbf{i}$ & 74,22 & 1,53 & $22,20 \mathbf{s}$ & 17,16 & 20,31 \\
\hline BR 23 & 78,44 & $131,56 \mathbf{s}$ & 53,11 & 91,89 & 79,00 & 1,42 & 20,88 & 17,26 & 24,23 \\
\hline BR 35 & 81,00 s & 126,67 & 45,67 & 91,89 & 79,22 & 1,49 & 19,28 & $19,78 \mathbf{s}$ & $19,71 \mathrm{~s}$ \\
\hline BRS 49 & 77,11 & 124,89 & 47,78 & $97,56 \mathbf{s}$ & 84,22 & 1,49 & 18,91 & 18,58 & 21,79 \\
\hline BRS 119 & 76,44 & 128,33 & 51,89 & 88,89 & 84,67 & 1,32 & $22,89 s$ & 18,78 & 21,96 \\
\hline BRS 120 & 78,33 & 128,11 & 49,78 & 92,56 & $111,89 \mathrm{~s}$ & 1,52 & $23,39 \mathbf{s}$ & 17,97 & 22,94 \\
\hline BRS 177 & $79,78 s$ & $130,22 s$ & 50,44 & 91,22 & $112,00 \mathrm{~s}$ & 1,30 & 21,44 & 18,38 & 22,82 \\
\hline BRS 194 & 74,78 & 126,44 & 51,67 & 93,33 & 90,44 & 1,35 & $16,57 \mathbf{i}$ & $16,57 \mathbf{i}$ & 23,76 \\
\hline BRS 208 & 72,67 & 123,44 & 50,78 & 85,89 & 84,33 & 1,30 & 20,62 & 18,11 & 22,35 \\
\hline CEP 24 & 72,44 & 121,33 & 48,89 & $103,33 \mathbf{s}$ & 82,44 & 1,39 & $22,79 s$ & $20,65 s$ & $26,62 \mathrm{~s}$ \\
\hline CEP 29 & 67,67 & 121,44 & 53,78 & 83,67 & 85,00 & 1,54 & 18,48 & 16,80 & $26,31 \mathrm{~s}$ \\
\hline BRS 192 & 71,67 & 123,44 & 51,78 & 84,78 & 78,67 & 1,48 & 20,38 & 17,15 & $19,34 \mathbf{i}$ \\
\hline PF950354 & 68,22 & 118,67 & 50,44 & $100,44 s$ & 80,56 & 1,32 & 18,83 & 17,42 & 23,61 \\
\hline RUBI & 73,78 & 119,11 & 45,33 & 89,11 & $109,67 \mathrm{~s}$ & 1,27 & 18,47 & $16,33 \mathbf{i}$ & $18,86 \mathbf{i}$ \\
\hline SONORA 64 & $56,56 \mathbf{i}$ & $103,00 \mathbf{i}$ & 46,44 & $80,00 \mathbf{i}$ & 80,22 & $1,15 \mathbf{i}$ & 18,73 & $16,01 \mathbf{i}$ & $19,69 \mathbf{i}$ \\
\hline TB 951 & 68,56 & $115,44 \mathbf{i}$ & 46,89 & $72,22 \mathbf{i}$ & 78,00 & $1,71 \mathrm{~s}$ & $22,47 \mathbf{s}$ & $16,34 \mathbf{i}$ & $17,83 \mathbf{i}$ \\
\hline ICA 1 & 66,56 & $117,78 \mathbf{i}$ & 51,22 & $99,11 \mathrm{~s}$ & 91,78 & 1,35 & 21,86 & $18,84 \mathrm{~s}$ & $29,43 s$ \\
\hline ICA 2 & $64,56 \mathbf{i}$ & 124,89 & $60,33 \mathbf{s}$ & 83,89 & 75,44 & 1,33 & $14,94 \mathbf{i}$ & $15,45 \mathbf{i}$ & $18,83 \mathbf{i}$ \\
\hline
\end{tabular}

$\mathrm{FV}(\mathrm{GL})$

\begin{tabular}{|c|c|c|c|c|c|c|c|c|c|}
\hline Genótipo(18) & $326,95^{\star}$ & $426,81^{\star}$ & $154,70^{*}$ & $615,42^{*}$ & $1276,64^{*}$ & $0,14^{*}$ & $46,13^{*}$ & $16,73^{*}$ & $83,06^{*}$ \\
\hline $\begin{array}{l}\text { QM Anos (2) } \\
Q M G \times A\end{array}$ & $2033,20^{*}$ & $4114,91^{*}$ & 767,86 & $3864,39^{*}$ & $6225,12^{*}$ & 0,71 & $311,65^{*}$ & $43,03^{*}$ & $275,31^{*}$ \\
\hline $\begin{array}{l}\text { (24) resíduo } \\
\text { QM res }\end{array}$ & $443,95^{*}$ & $602,46^{*}$ & $118,88^{*}$ & $85,61^{*}$ & $345,16^{*}$ & $0,03^{*}$ & $8,71^{*}$ & $2,10^{\star}$ & $9,55^{\star}$ \\
\hline 3) & 27,82 & 38,08 & 31,01 & 15,86 & 194,06 & 0,01 & 2,04 & 0,63 & 2,99 \\
\hline VV (\%) & 7,30 & 5,00 & 11,00 & 4,56 & 16,13 & 6,37 & 7,10 & 4,47 & 7,74 \\
\hline lédia & 72,45 & 123,29 & 50,81 & 89,91 & 86,35 & 1,40 & 20,12 & 17,71 & 22,32 \\
\hline nplitude & 34,84 & 42,17 & 10,95 & 40,36 & 48,16 & 0,73 & 8,94 & 5,78 & 13,53 \\
\hline MS (5\%) & 7,00 & 5,30 & 7,55 & 6,73 & 19,33 & 0,15 & 2,04 & 1,12 & 2,39 \\
\hline
\end{tabular}

(+) DEF - dias da emergência ao florescimento, DEM - dias da emergência a maturação, DFM - dias do florescimento a maturação, EP- estatura de planta, AFML - número de afilhos férteis por metro linear, LFB - largura da lâmina da folha bandeira, CFB - comprimento da lâmina da folha bandeira, CB-comprimento da bainha e CP - comprimento do pedúnculo. Médias seguidas por s e inas colunas, são superiores ou inferiores, respectivamente, a média do caráter a $5 \%$ de probabilidade de erro pelo teste DMS. ${ }^{*}=$ significativo a $5 \%$ de probabilidade de erro pelo teste $\mathrm{F}$.

Os resultados também evidenciaram a existência de uma ampla variação (amplitude) entre os valores máximos e mínimos dos genótipos, para a maioria dos caracteres aferidos (Tabelas 2 e 3). Em exame dos maiores e menores valores em cada caráter, foi constatado que alguns genótipos apresentam médias situadas nos limites superiores e inferiores para um grande número de caracteres. Neste sentido, merece destaque o genótipo Sonora 64 que evidenciou valores médios situados no limite inferior de variação para nove dentre os 17 caracteres aferidos (DEF, DEM, EP, LFB, CB, CP - Tabela 2; e
RG, PE, PMG - Tabela 3) e o genótipo TB 951 que expressou valores de média situados nos limites de variação inferior para os caracteres $D E M, E P, C B, C P$ e $R G$ e no limite superior de variação para os caracteres LFB, CFB, CE e NG. Isto é um indicativo de que tais constituições genéticas são bem divergentes em relação as demais para os caracteres fenotípicos. Dentre os caracteres avaliados, somente um (NG NE-1) não revelou genótipos com médias significativamente inferiores e superiores a média geral, segundo o teste de comparação de médias DMS (Tabelas 2 e 3). 
BERTAN, I. et al. Variabilidade genética em trigo...

TABELA 3 - Comparação de médias e resumo das análises de variância de oito caracteres avaliados em 19 genótipos de trigo. CGF/ UFPEL, Pelotas, 2007.

\begin{tabular}{|c|c|c|c|c|c|c|c|c|}
\hline \multirow[b]{2}{*}{ Genótipos } & \multicolumn{8}{|c|}{ Caracteres } \\
\hline & $\begin{array}{c}\mathrm{RG}^{(+)} \\
\left(\mathrm{kg} \mathrm{ha}^{-1}\right)\end{array}$ & $\begin{array}{c}\mathrm{PH} \\
\left(\mathrm{kg} \mathrm{hl}^{-1}\right)\end{array}$ & $\begin{array}{c}\text { NE } \\
\text { (unid.) }\end{array}$ & $\begin{array}{c}\mathrm{CE} \\
(\mathrm{cm})\end{array}$ & $\begin{array}{l}P E \\
\text { (g) }\end{array}$ & $\begin{array}{c}\text { NG } \\
\text { (unid.) }\end{array}$ & $\begin{array}{l}\text { NG NE-1 } \\
\text { (unid.) }\end{array}$ & $\begin{array}{c}\text { PMG } \\
\text { (g) }\end{array}$ \\
\hline $\mathrm{BH} 1146$ & $2046,05 i$ & 73,62 & 15,53 & 8,93 & 1,81 & 33,64 & 2,17 & 39,28 \\
\hline BR 18 & $1954,82 \mathbf{i}$ & $71,62 \mathbf{i}$ & 15,04 & 8,58 & 2,00 & 32,21 & 2,15 & $44,05 \mathrm{~s}$ \\
\hline BR 23 & 3111,23 & 76,44 & 17,49 & 9,92 & 2,20 & 39,51 & 2,28 & 40,93 \\
\hline BR 35 & 2991,48 & 74,13 & 16,43 & 8,31 & 2,07 & 38,01 & 2,30 & 41,89 \\
\hline BRS 49 & 2408,15 & 72,76 & 17,52 & 8,14 & 1,97 & 39,71 & 2,27 & 37,50 \\
\hline BRS 119 & 2482,22 & 74,98 & 16,58 & 8,63 & 2,05 & 40,51 & 2,43 & 36,41 \\
\hline BRS 120 & 2811,61 & 75,42 & 15,89 & 8,79 & 1,88 & 34,13 & 2,15 & 38,27 \\
\hline BRS 177 & $3803,90 \mathrm{~s}$ & 76,73 & 16,04 & 9,01 & 1,78 & 37,89 & 2,37 & 34,62 \\
\hline BRS 194 & 2969,33 & 73,18 & 17,02 & $7,43 \mathbf{i}$ & 1,99 & 37,42 & 2,20 & 39,69 \\
\hline BRS 208 & 3021,60 & 75,02 & 15,84 & 8,09 & 2,12 & 38,93 & 2,45 & $42,69 \mathrm{~s}$ \\
\hline CEP 24 & 2726,30 & 75,87 & 15,78 & 8,69 & 1,96 & 34,11 & 2,17 & $46,68 \mathrm{~s}$ \\
\hline CEP 29 & 2940,00 & 75,31 & 16,02 & 9,13 & 2,27 & 42,38 & 2,65 & 38,62 \\
\hline BRS 192 & 2806,88 & 76,73 & 15,62 & 8,57 & 2,17 & 40,60 & 2,59 & 35,34 \\
\hline PF950354 & 2437,78 & 74,93 & 17,49 & $10,30 \mathrm{~s}$ & 2,07 & 38,53 & 2,21 & 37,44 \\
\hline RUEI & $3300,74 \mathrm{~s}$ & $78,24 \mathrm{~s}$ & $14,68 \mathbf{i}$ & $7,85 \mathbf{i}$ & 1,70 & 33,95 & 2,31 & 34,75 \\
\hline SONORA 64 & $1931,48 \mathbf{i}$ & 69,98 & 15,24 & 8,29 & $1,44 \mathbf{i}$ & 30,49 & 2,01 & $32,89 \mathbf{i}$ \\
\hline TВ 951 & $2172,65 \mathbf{i}$ & 74,44 & 18,36 & $13,83 \mathrm{~s}$ & 2,39 & $46,98 \mathrm{~s}$ & 2,55 & 34,32 \\
\hline ICA 1 & 2650,25 & 75,09 & 16,24 & 8,15 & 1,87 & 38,14 & 2,34 & 34,15 \\
\hline $\mathrm{ICA} 2$ & 2507,16 & 74,11 & 16,49 & 8,46 & 1,90 & 39,48 & 2,40 & 34,93 \\
\hline \multicolumn{9}{|l|}{$\mathrm{FV}(\mathrm{GL})$} \\
\hline QM Genótipo(18) & $209084,95^{\star}$ & $33,13^{*}$ & $8,17^{\star}$ & $16,85^{*}$ & $0,42^{*}$ & $137,76^{*}$ & $0,25 *$ & $129,17^{*}$ \\
\hline QM Anos (2) & $338542,76^{*}$ & $44,42^{*}$ & 6,83 & 2,89 & $0,98^{*}$ & $472,80^{*}$ & $1,10^{*}$ & 88,61 \\
\hline QM GXA (24) & $74501,58^{*}$ & $12,87^{*}$ & 1,54 & 5,27 & $0,13^{*}$ & $43,43^{*}$ & $0,12^{*}$ & $35,72^{*}$ \\
\hline QM residuo (53) & 9678,46 & 2,07 & 0,77 & 10,19 & 0,57 & 17,89 & 0,05 & 10,99 \\
\hline $\mathrm{CV}(\%)$ & 11,55 & 1,93 & 5,41 & 15,86 & 12,14 & 11,21 & 9,74 & 8,69 \\
\hline Média & 2688,08 & 74,66 & 16,26 & 8,90 & 1,98 & 37,72 & 2,32 & 38,12 \\
\hline Amplitude & 2461,97 & 9,62 & 3,97 & 3,87 & 1,04 & 20,16 & 0,69 & 10,37 \\
\hline DMS (5\%) & 471,40 & 2,37 & 1,36 & 0,93 & 0,43 & 6,67 & 0,36 & 4,49 \\
\hline
\end{tabular}

${ }^{(+)} \mathrm{RG}$ - rendimento de grão, $\mathrm{PH}$ - peso do hectolitro, NE - número de espiguetas, $\mathrm{CE}$ - comprimento da espiga, PE - peso da espiga, NG - número de grãos por espiga, NG NE-1 - número de grãos por espigueta e PMG - peso de mil grãos. Médias seguidas por $s$ e i nas colunas, são superiores ou inferiores, respectivamente, a média do caráter a $5 \%$ de probabilidade de erro pelo teste DMS. ${ }^{*}=$ significativo a $5 \%$ de probabilidade de erro pelo teste $\mathrm{F}$.

Em relação à distância de Mahalanobis $\left(\mathrm{D}^{2}\right)$, estimada por meio dos caracteres fenotípicos, os genótipos mais distantes foram TB 951 e BRS 35 e os menos distantes foram BRS 119 e BRS 208 (dados não apresentados, verificados na matriz de distância genética). $O$ dendrograma evidenciou que o genótipo que mais distanciou em relação aos demais foi o Sonora 64 (Figura 1-A). O fato deste genótipo se diferenciar dos demais em relação aos caracteres fenotípicos já era esperado, pois o mesmo apresenta médias situadas nos limites inferiores para um grande número de caracteres fenotípicos (nove). O coeficiente de correlação cofenética do dendrograma $(r=0,80)$ revelou um bom ajuste entre a representação gráfica das distâncias e a sua matriz original, o que justifica que sejam realizadas inferências por meio da avaliação visual da Figura 1-A. Resultados semelhantes aos obtidos no presente trabalho foram verificados também em trigo por BERED et al. (2001), MÁRIC et al. (2004) e ROY et al. (2004). Estas pesquisas utilizaram genótipos distintos daqueles empregados no presente estudo, e evidenciaram existir variabilidade genética por meio do emprego de caracteres fenotípicos. O fato dos estudos de distância genética com base fenótipo das plantas revelar na maioria das vezes diferenças entre os genótipos empregados nas análises pode 
BERTAN, I. et al. Variabilidade genética em trigo...

ser justificado pelo constante progresso dos trabalhos de melhoramento genético realizado nas distintas regiões de cultivo do trigo, tanto em nível nacional quanto internacional. Isto eleva grandemente a possibilidade da amostragem de genótipos com potencial fenotípico diferenciado, principalmente por apresentarem genitores contrastantes geneticamente nas suas origens.
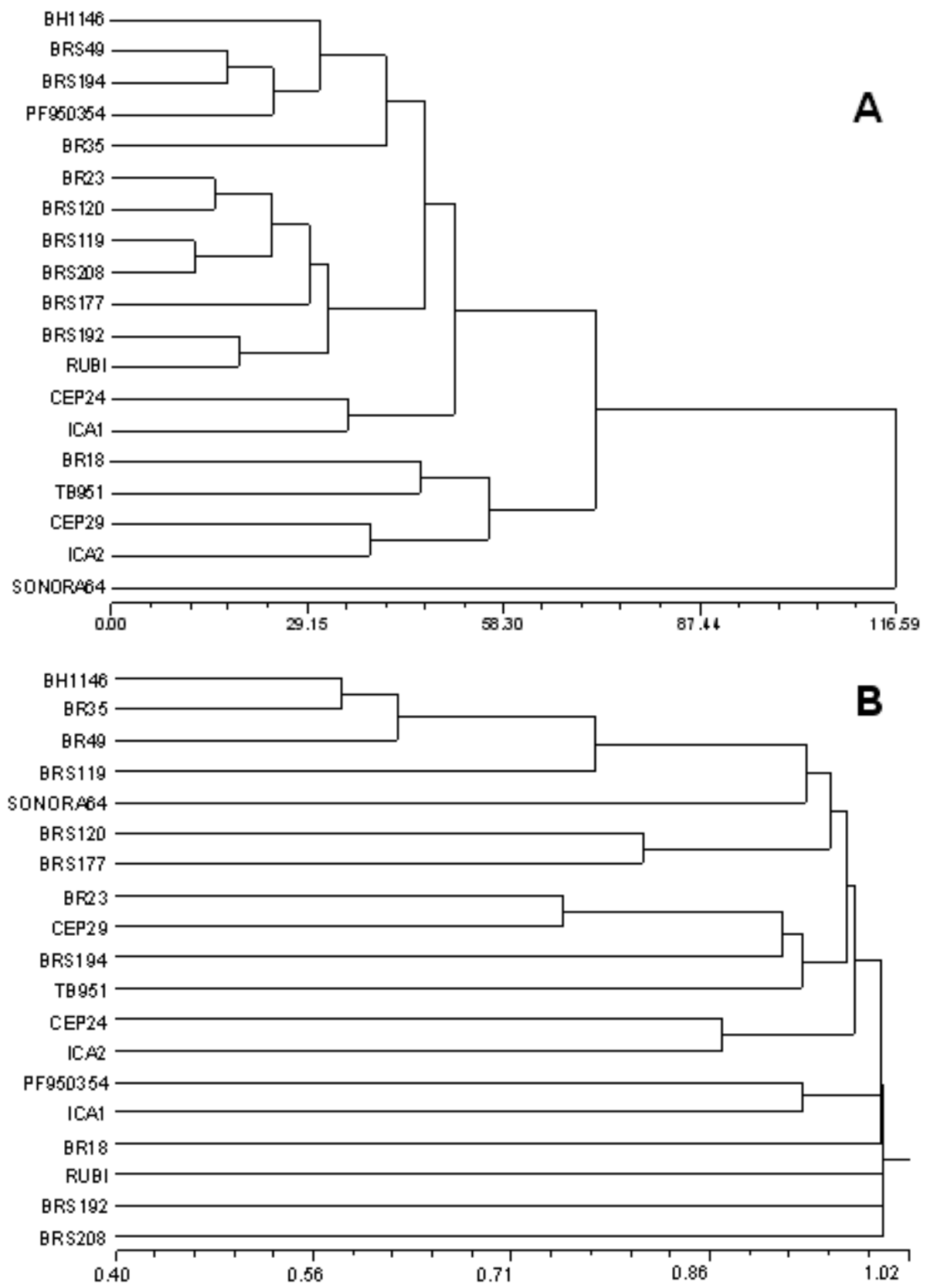

FIGURA 1 - Dendrogramas resultantes da análise de 19 genótipos de trigo, obtido pelo método de agrupamento UPGMA, empregando: A - a distância de Mahalanobis (com base em 17 caracteres fenotípicos) como medida de distância genética e B - os coeficientes de parentesco (COP) obtidos por meio do sistema de cálculo de Malécot. Os valores do coeficiente de correlação cofenética ( $r$ ) são de: $A=0,80$ e $B=0,90$. CGF/UFPEL, Pelotas, 2007. 
O dendrograma resultante da matriz de coeficientes de parentesco (COP) evidenciou que os genótipos mais próximos foram BH 1146 e BR 35 e os mais distantes em relação aos demais foram $B R$ 18, RUBI, BRS 192 e BRS 208 (Figura 1-B). Este grupo de maior distância apresentou coeficientes de parentesco iguais a zero, ou seja, não possuem relações comuns de parentesco entre si e para com os demais genótipos avaliados; ou ainda, não há informações detalhadas referentes as suas genealogias, o que implica em não realizar inferências a respeito destes genótipos por meio do coeficiente de parentesco. Os genótipos BH 1146, BR 35 e BR 49 foram os que apresentaram maior grau de parentesco, ao passo que o restante dos genótipos formaram agrupamentos com elevada distância genealógica, revelando reduzidas relações de genealogia entre seus genitores. Resultados semelhantes foram obtidos por BERED et al. (2001) avaliando 40 cultivares e 10 linhagens de trigos brasileiros, sendo que alguns genótipos coincidem aos avaliados no presente trabalho $(\mathrm{BH} 1146$, BR 18, BR 23, BR 35, CEP 24 e Sonora 64). O coeficiente de correlação cofenética do dendrograma $(r=0,91)$ mostrou um ótimo ajuste entre a representação gráfica das distâncias e a sua matriz original, o que implica em elevada segurança na realização de inferências a partir da análise visual da Figura 1-B.

Atendendo a um dos objetivos da análise de distância genética que é a recomendação de combinações híbridas para cruzamentos, os resultados deste trabalho possibilitam inferir com maior segurança mediante a análise dos caracteres fenotípicos e tendo o coeficiente de parentesco como auxiliar. Desta forma, o genótipo mais divergente em relação aos demais é o Sonora 64 (Figuras 1-A); contudo, quando da recomendação de cruzamento, tal genótipo não deve ser priorizado em função do mesmo ter evidenciado o menor rendimento de grãos (Tabela 2). Dentre os caracteres mais visados no melhoramento de plantas, estão os relacionados à produtividade de grãos ( $R G$ e $\mathrm{PH}$ ), que determinam o desempenho final e recomendação das novas cultivares. Para tais caracteres, a indicação de cruzamento com intuito de elevar o platô de produtividade de grãos deve incluir genótipos com elevado $R G$ e $P H$, porém divergentes genealogicamente e para o conjunto de caracteres fenotípicos avaliados. Desta maneira, é esperado que estes genótipos possuam genes diferentes controlando estes caracteres, e que quando combinados em uma nova constituição genética possam resultar em progênies com desempenho superior aos seus genitores, ou seja, progênies segregantes transgressivas. Neste contexto, merece destaque os cruzamentos que envolvam os genótipos BRS 177 (superior para RG) e o Rubi (superior para $R G$ e $P H)$ (Tabela 2), que aliado ao desempenho superior nestes caracteres, evidenciam divergência genética em relação a maioria dos demais genótipos empregados no presente estudo (Figura 1).

Em relação as duas estimativas de distância genética empregadas no estudo, a estimativa de correlação (associação) entre ambas revelou valor reduzido e não significativo $(r=0,13)$, sugerindo que estas técnicas não concordam quando empregadas em genótipos de trigos sul-brasileiros. Resultados semelhantes indicando reduzida associação entre estas duas medidas de distância genética em trigo foram também encontrados por BARBOSA NETO et al. (1996) e BOHN et al. (1999). Em aveia (Avena sativa L.), resultados de pesquisa sugerem que para a obtenção de estimativas mais seguras de distância genética é necessário considerar conjuntamente os dados fenotípicos e genalógicos (VIEIRA et al., 2005), apesar da reduzida associação verificada entre estas duas estimativas de distância $(r=-, 0,15$ e 0,06 entre dados genealógicos $x$ caracteres fenotípicos com aplicação de fungicida para controle de moléstias e genealógico x caracteres fenotípicos sem aplicação de fungicida, respectivamente). Em um exemplo específico reportado em milho (GERDES e TRACY, 1994), foi verificado associações significativas entre a distância genealógica e caracteres fenotípicos (0,31 ), porém, com coeficiente negativo e de magnitude não expressiva. Os dados deste estudo são justificados pelo fato de incluir constituições genéticas de um mesmo grupo heterótico e genealogicamente oriundas de um grupo reduzido de genitores, o que proporcionou a estimativa de elevados coeficientes de parentesco e reduzida distância morfológica e também molecular.

A reduzida associação entre dados fenotípicos e genealógicos verificados no presente estudo pode ser explicados de diferentes maneiras: i) os genótipos avaliados fazem parte de um "pool" gênico constituído por trigos modernos, cujos caracteres morfológicos diferem daqueles genótipos introduzidos no Brasil na década de 70 e 80 , os quais também fazem parte da genealogia utilizada para estimativa do coeficiente de parentesco do presente estudo; ii) a real inexistência de relações genealógicas entre dois genótipos, mediante a estimativa do coeficiente de parentesco, não implica em divergência para um conjunto de caracteres morfológicos; iii) a dificuldade na obtenção de informações a respeito da genealogia de alguns genótipos implica na dificuldade de estimar coeficientes de parentesco precisos. Genótipos estes, em muitos casos, participam em percentuais expressivos na constituição genética dos genótipos avaliados. Estes aspectos implicam na utilização complementar da distância genealógica quando da orientação dos cruzamentos artificiais em programas de melhoramento genético de trigo.

\section{CONCLUSÃO}

Existe variabilidade genética entre os genótipos de trigos sul-brasileiros, comprovado mediante a análise de caracteres fenotípicos e pelo coeficiente de parentesco.

A estimativa de distância genética com base em caracteres fenotípicos não é associada com a distância considerando o coeficiente de parentesco. 
BERTAN, I. et al. Variabilidade genética em trigo...

Os genótipos BRS 177 e Rubi apresentam elevado rendimento de grãos e são divergentes geneticamente em relação a maioria dos demais avaliados no estudo, devendo ser priorizados em cruzamentos artificiais com a finalidade de promover o incremento da produtividade de grãos em trigo.

\section{REFERÊNCIAS}

1. BARBOSA NETO, J.F.; SORRELLS, M.E.; CISAR, G. Prediction of heterosis in wheat using coefficient of parentage and RFLP based estimates of genetic relationship. Genome, Montreal, v. 39, n .6, p. 1142-1149, 1996.

2. BERED, F.; BARBOSA NETO, J.F.; ROCHA, B.M.; CARVALHO, F.I.F. Genetic Variability in Common Wheat Based on Morphological Traits, Coefficients of Parentage and RAPDs. Journal of New Seeds, Binghamton, v. 3, n. 2, p. 73-87, 2001.

3. BERTAN, I. Distância genética como critério para escolha de genitores em programas de melhoramento de trigo (Triticum aestivum L.). Pelotas, 2005. 93 f. Dissertação (Mestrado) - Faculdade de Agronomia Eliseu Maciel, Universidade Federal de Pelotas.

4. BOHN, M.;FRIEDRICH, H.; MELCHINGER, A.E. Genetic similarities among Winter wheat cultivars determined on basis of RFLPs, AFLPs, SSRs and their use for predicting variance. Crop Science, Madison, v. 39, n. 1, p. 228-237, 1999.

5. COMISSÃO SUL BRASILEIRA DE PESQUISA DE TRIGO. Indicações técnicas da Comissão Sul-Brasileira de Pesquisa de Trigo. Passo Fundo: Embrapa Trigo, 2002. 74 p.

6. CRUZ, C.D. Programa genes: aplicativo computacional em genética e estatística. Viçosa: UFV, 2001. $648 \mathrm{p}$

7. GERDES, J.T.; TRACY, W.F. Diversity of historically important sweet corn inbreds as estimated by RFLPs, morphology, isozymes, and pedigree. Crop Science, Madison, v. 34, n. 1, p. 26-33, 1994

8. MANTEL, N. The detection of disease clustering and a generalized regression approach. Cancer Research, Chestnut, v. 27, n. 2, p. 209-220, 1967

9. MÁRIC, S.; BOLARÍC, S.; MARTINCIC, J.; et al Genetic diversity of hexaploid wheat cultivars estimated by RAPD markers, morphological traits and coefficients of parentage. Plant Breeding, Berlin, v. 123, n. 4, p. 366-369, 2004.

10. MOHAMMADI, S.A.; PRASANNA, B.M. Analyses of genetic diversity in crop plants - Salient statistics tools and considerations. Crop Science, Madison, v. 43, n. 4, p. 1235-1248, 2003.

11. PINZÓN-ALMANZA, M.I.; KHAIRALLAH, M.; FOX, P.N.; et al. Comparison of molecular markers and coefficients of parentage for the analysis of genetic diversity among spring bread wheat acessions. Euphytica, Dordrecht, v. 130, n. 1, p. 77-86, 2003.

12. ROHLF, F.J. NTSYS-pc: numerical taxonomy and multivariate analysis system, version 2.1. New York: Exeter Software, $2000.83 \mathrm{p}$.

13. ROY, J.K.; LAKSHMIKUMARAN, M.S.; BALYAN, H.S.; et al AFLP-based genetic diversity and its comparison with diversity based on SSR, SAMPL, and phenotypic traits in bread wheat. Biochemical Genetics, New York, v. 42, n. 1-2, p. 43-59, 2004.

14. SAS LEARNING EDITION. Getting started with the SAS Learning Edition Cary. SAS Institute Inc., 2002.

15. SCHEEREN, P.L. Instruções para utilização de descritores de trigo (Triticum sp.) e triticale (Triticun sp.). Passo Fundo: EMBRAPA-CNPT, 1984. 32 p. (EMBRAPA-CNPT. Documentos, 9).

16. SOKAL, R.R.; ROHLF, F.J. The comparison of dendrograms by objective methods. Taxon, Berlin, v. 11, n. 1, p. 30-40, 1962.

17. SHUT, J.W.; STAM, P. Association between relationship measures based on AFLP markers, pedigree data and morphological traits in barley. Theoretical and Applied Genetics, New York, v. 95, n. 7, p. 1161-1168, 1997.

18. VAN BEUNINGEN, L.T.; BUSH, R.H. Genetic diversity among North American spring wheat cultivars: III. Cluster analysis based on quantitative morphological traits. Crop Science, Madison, v. 37, n. 3, p. 981-988, 1997.

19. VIEIRA, E.A.; CARVALHO, F.I.F.; OLIVEIRA, A.C.; BENIN, G.; ZIMMER, P.D.; SILVA, J.A.G.; MARTINS, A.F.; BERTAN, I.; SILVA, G.O.; SCHIMIDT, D.A.M.. Comparação entre medidas de distância genealógica, morfológica e molecular em aveia (Avena sativa) em experimentos com e sem a aplicação de fungicida. Bragantia, Campinas, v. 64, n. 1, p. 51-60, 2005.

20. ZEVEN, A., REINER, L. Geneologies of $\mathbf{3 2 0 0}$ wheat varieties. Wageningen: Institute of Plant Breeding-I.v.P., Agricultural University; Munich: Crop Husbandry, Technical University Munich, 1991. 79 p.

21. ZEVEN, A.C.; SCHACHL, R. Groups of bread wheat landraces in the Australian Alps. Euphytica, Dordrecht, v. 41, p. 235-246, 1989.

22. ZEVEN. A., ZAVEN-HISSINK, N.C. Genealogies of $\mathbf{1 4 0 0 0}$ wheat varieties. Wageningen: The Netherlands Cereal Centre; Mexico: International Maize and Wheat Improvement Center, 1976. 121 p. 